\title{
Unequal Efficacy of Pyridinium Oximes in Acute Organophosphate Poisoning
}

\author{
Biljana Antonijevic and Milos P. Stojiljkovic
}

\begin{abstract}
The use of organophosphorus pesticides results in toxicity risk to non-target organisms. Organophosphorus compounds share a common mode of action, exerting their toxic effects primarily via acetylcholinesterase ( $\mathrm{AChE}$ ) inhibition. Consequently, acetylcholine accumulates in the synaptic clefts of muscles and nerves, leading to overstimulation of cholinergic receptors. Acute cholinergic crisis immediately follows exposure to organophosphate and includes signs and symptoms resulting from hyperstimulation of central and peripheral muscarinic and nicotinic receptors. The current view of the treatment of organophosphate poisoning includes three strategies, i.e. the use of an anticholinergic drug (e.g., atropine), cholinesterase-reactivating agents (e.g., oximes) and anticonvulsant drugs (e.g., benzodiazepines). Oximes, as a part of antidotal therapy, ensure the recovery of phosphylated enzymes via a process denoted as reactivation of inhibited AChE. However, both experimental results and clinical findings have demonstrated that different oximes are not equally effective against poisonings caused by structurally different organophosphorus compounds. Therefore, antidotal characteristics of conventionally used oximes can be evaluated regarding how close the certain substance is to the theoretical concept of the universal oxime. Pralidoxime (PAM-2), trimedoxime (TMB-4), obidoxime (LüH-6), HI-6 and HLö-7 have all been demonstrated to be very effective in experimental poisonings with sarin and VX.TMB-4 and LüH-6 may reactivate tabun-inhibited AChE, whereas HI-6 possesses the ability to reactivate the soman-inhibited enzyme. An oxime HLö-7 seems to be an efficient reactivator of AChE inhibited by any of the four organophosphorus warfare agents. According to the available literature, the oximes LüH-6 and TMB-4, although relatively toxic, are the most potent to induce reactivation of $\mathrm{AChE}$ inhibited by the majority of organophosphorus pesticides. Since there are no reports of controlled clinical trials on the use of TMB-4 in human organophosphate pesticide poisoning, LüH-6 may be a better option.
\end{abstract}

Keywords: Antidotal therapy; Efficacy; Organophosphates; Organophosphorus insecticides; Oximes; Reactivation

$\mathrm{H}$ ighly toxic organophosphorus compounds (OPCs) are widely used for pest control and for the control of vector-borne diseases. These compounds also include the nerve poisons that are among the most toxic group of chemical warfare agents. Toxicology of organophosphates, as well as the therapeutic approaches in acute organophosphate poisoning, is of importance to many different groups of health professionals. The management of OPC poisoning is complex and includes nonspecific and specific measures. The dominant underlying toxicodynamic mechanism in organophosphate poisoning is inhibition of acetylcholinesterase

Reprint Requests: Biljana Antonijevic, Institute of Toxicological Chemistry, Faculty of Pharmacy, University of Belgrade, Vojvode Stepe 450, II22I Belgrade, Serbia, Tel: 38I-II-3970389/ext 650, Fax: 38I-II-3972840, Email: abiljana@pharmacy.bg.ac.yu
(AChE). Oximes, as cholinesterase reactivators, are the only causal antidotes used against OPCs. Unfortunately, there are no known oximes that are efficient reactivators of cholinesterase inhibited by any of the known OPCs. Moreover, controlled clinical studies proving the efficacy of oximes in humans are mostly lacking.

\section{Historical Overview}

The first synthesis of an OPC was performed in the middle of the 19th century by Moschnine in Professor Wurtz's laboratory in Paris. The first OPC ever synthesized was tetraethylpyrophosphate and the process was first published

DOI: $10.3|2| / \mathrm{cmr} .2007 .70 \mid$ 
<smiles>CCOP(=O)(C#N)N(C)C</smiles>

Tabun<smiles>CC(C)OP(C)(=O)F</smiles>

Sarin<smiles>CC(OP(C)(=O)F)C(C)(C)C</smiles>

Soman $\mathbf{C H}_{3}$<smiles>CCOP(C)(=O)SCCN(C(C)C)C(C)C</smiles>

VX<smiles>CCN(CC)CCSP(C)(=O)OCC(C)C</smiles>

Russian VX

(VR)

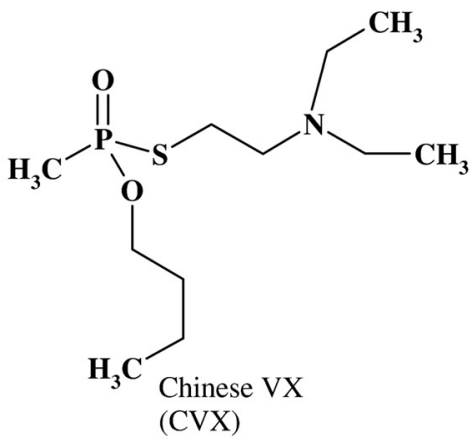

Figure 1. Structural formulas for organophosphorus chemical warfare agents.

in 1854 by de Clermont. However, von Hofmann was the first scientist to synthesize an OPC with direct phosphorus-carbon linkage (methylphosphoryl dichloride) in 1873. In the next century, Lange and von Krueger synthesized dialkylphosphonofluoridates, obtaining many OPCs with insecticidal or fungicidal properties. Between 1934 and 1944 Schrader's team synthesized approximately 2000 OPCs and in 1944 two well-known organophosphorus insecticides, diethyl- $p$-nitrophenylphosphate (paraoxon, E600) and diethyl-p-nitrophenylthiophosphate (parathion, E605), were synthesized. As early as 1935, the Nazi Germany government insisted on redefining Schrader's primal aim from organophosphorus insecticides to organophosphorus chemical warfare agents (e.g., tabun, sarin, soman). In a series of fluorine-containing esters, besides sarin and soman, Schrader also developed diisopropyl phosphorofluoridate (DFP). Also during this same period, British and American scientists were evaluating the toxic properties of DFP and other alkyl phosphorofluoridates. Although initially designed as a potential chemical warfare agent, DFP became a model substance widely used throughout the pharmacological community for studying cholinergic neurotransmission. The fourth chemical warfare agent, VX, was synthesized a decade later in 1957 by Tammelin. ${ }^{1}$

During the same period, Russian scientists developed the so-called Russian VX (VR). Another structural analog of VX, known as Chinese VX (CVX), was also developed. Kuca and co-workers ${ }^{2}$ showed that the VX agent was half-fold more toxic in comparison with VR with in vitro experiments using rat, pig and human brain homogenate. However, examination of reactivity towards human and pig AChE demonstrated the following rank order of inhibitory potency: $\mathrm{VR}>\mathrm{CVX}>\mathrm{VX} .{ }^{3}$ Structural formulae of some organophosphorus chemical warfare agents are given in figure 1.
In the late 1980s and early 1990s, chemists in Russia produced several new agents, including Novichok-5 and Novichok-7. According to the Russian scientist-defector Mirzayanov, Novichoks are binary nerve agents, i.e., agents that become lethal only after mixing of the two otherwise benign components, and their toxicity is allegedly 10 to 100 times greater than one of the conventional nerve agents. Unlike VX, Novichok's reactivability with oximes seems to be at least as difficult as in soman poisoning. The intermediate volatility agent also belongs to the group of organophosphate nerve agents. ${ }^{4}$ To our knowledge, there are no peer reviewed, scientific articles concerning chemical and toxicological properties of Novichoks and intermediate volatility agents, although there are some press reports on them.

After World War II, OPCs were reintroduced worldwide for pesticide use, as originally intended. In the decades since, numerous structurally different OPCs have been synthesized. Currently more than 100 different OPCs are used mainly as insecticides in agriculture and gardening. ${ }^{5-7}$

\section{Toxicological Relevance}

In industrialized countries, severe intoxication of OPCs generally results from oral intake, whereas inhalation or dermal absorption does not play a major role. In developing countries, the most common cause of pesticide poisonings is due to occupational exposure. However, a review of poisoning studies in developing countries reveals that pesticide poisonings associated with high mortality rates are usually the result of self-poisoning. Particularly, a great number of victims was present in rural regions due to the widespread availability of acutely toxic pesticides used in agriculture. 8,9 Organophosphorus pesticides cause several hundreds of thousands of victims per year worldwide. ${ }^{6}$ While some of these intoxications may be attributed to accidental exposure, 


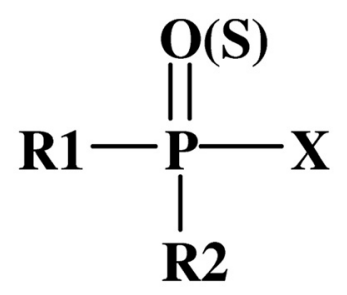

Figure 2. Schrader's formula for organophosphorus compounds.

the majority of casualties result from suicidal attempts with ingestion of multiple lethal doses. Therefore, the indiscriminate use of these pesticides results in a toxicity risk to non-target organisms and environmental pollution.

Due to their high toxicity, OPCs bear a potential risk for use in war conflicts and terrorist attacks. Namely, the repeated use of nerve agents during the Iran-Iraq war in the $1980 \mathrm{~s},{ }^{10}$ against civilians by Iraqi troops, ${ }^{11}$ and during terrorist attacks by the Aum Shinrikyo sect in Japan ${ }^{12-15}$ emphasize the constant threat and need for increased awareness of the potential for future homicidal attempts, as well as the urgent need for the development of an effective medical treatment regimen. ${ }^{16,17}$

The mechanism of action of OPCs, as well as factors contributing to toxic response, will be briefly discussed in this paper. Treatment of acute poisoning caused by this class of substances will be considered through a correlation of experimental data and clinical findings, with special attention to oxime efficacy against chemically different cholinesterase inhibitors.

\section{Mechanism of Action of OPCs}

The basic chemical structure of all OPCs is described by Schrader's formula (figure 2). ${ }^{18}$ The structural diversity of OPCs is due to different substituents at the phosphorus atom. Substituents at R1 and R2 are alkyl, alkoxy, alkylthio or amino groups, and substituent at $X$ is a labile acyl residue (halide, cyano, phenol or thio group), known as the leaving group.

The reactivity of OPCs varies upon chemical structure. Electrophilicity of the phosphorus atom is crucial for the biological actions of OPCs. Organophosphates that have double bonds between phosphorus and oxygen atoms are highly electrophilic at the phosphorus atom and accordingly are highly reactive. Groups that enhance the reactivity of the phosphorus atom are nitro, cyano, halogen, ketone and carboxylic ester. Deactivating groups include hydroxyl and carboxylic acid. Organophosphates share a common mode of action, ${ }^{19}$ exerting their toxic effects primarily via AChE (EC 3.1.1.7) inhibition. ${ }^{20-22}$ Cholinesterases are hydrolytic enzymes whose existence was first proposed by Sir Henry Hallet Dale in 1914. ${ }^{23}$ During his research on cholinergic mechanisms, he proposed that "in the blood at body temperature an esterase contributed to the removal of the active ester from the circulation." The butyrylcholinesterase (BuChE, EC 3.1.1.8) and AChE are both blocked by OPCs. Although both cholinesterases hydrolyze acetylcholine (ACh) and other choline esters, they differ in their relative affinity for some substrates. AChE is an enzyme of vital importance, as well as one of the most efficient enzymes known. A single enzyme molecule is capable of hydrolyzing $6 \times 10^{5}$ molecules of ACh per minute. Muscle and nerve $\mathrm{AChE}$ are only present in the synaptic cleft and cannot be measured directly. Since erythrocyte AChE has a similar structure as the synaptic enzyme, it appears to be a suitable parameter to reflect various reactions at the synaptic site. ${ }^{24,25}$ Therefore, its measurement is of high value for therapeutic management, especially oxime administration, during the course of intoxication. ${ }^{17}$

Inhibition of $\mathrm{BuChE}$, whose physiological role is still unclear, can be ascertained by clinical laboratory procedures and will confirm the clinical diagnosis. Even more, BuChE has been recognized as a bioscavenger of OPCs, thereby decreasing the organophosphate concentration in the organism. ${ }^{26}$ Namely, among the enzymes examined as potential scavengers of OPCs, significant advances have been made by using AChE and BuChE. ${ }^{27-29}$ Human serum BuChE is proposed as an exogenously administered prophylactic for human use ${ }^{30}$ due to the following facts: it reacts rapidly with all highly toxic OPCs, offering a broad range of protection for nerve agents including soman, sarin, tabun and VX; it possesses a very long retention time in human circulation and is readily absorbed from sites of injection; the enzyme is from a human source and should not produce any adverse immunological responses upon repeated administration to humans. ${ }^{31}$ However, the production of native human $\mathrm{BuChE}$ requires large amounts of plasma leading to the development of technologies to produce recombinant human BuChE. ${ }^{32}$

Despite the fact that both $\mathrm{AChE}$ and $\mathrm{BuChE}$ serve as diagnostic tools, after the exposure resulting in inhibition levels $<20 \%$ with no clinical signs and symptoms of organophosphate poisoning, it is necessary to bear in mind the uncertainty due to marked inter-individual variations of $\mathrm{AChE}$ and $\mathrm{BuChE}$ activities and to intra-individual variation of BuChE activities. ${ }^{16,33}$ Another factor complicating the interpretation of erythrocyte AChE activity is that inhibition of this enzyme probably overestimates the inhibition of AChE in the nervous system. ${ }^{33}$ Namely, in the case of an irreversible inhibition, recovery of erythrocyte $\mathrm{AChE}$ depends on de novo production and release from the bone marrow of new erythrocytes with uninhibited $\mathrm{AChE}$. The recovery rate of erythrocyte $\mathrm{AChE}$ has been estimated to be $1 \%$, whereas the half-life of AChE resynthesis in the nervous system has been reported to be 5 to 7 days. Therefore, AChE in brain will recover earlier than in red blood cells.

\section{Molecular Mechanisms of Organophosphate Toxicity \\ OPCs and their active metabolites are electrophilic molecules with moderate to high potency for phosphylation (denotes both phosphorylation and phosphonylation) of the serine hydroxyl group located at the active site of AChE. This phosphylation occurs by the loss of the leaving group and the establishment of a covalent bond with AChE through the serine hydroxyl. The resultant phosphylated AChE is typically}


very stable and is only slowly regenerated by spontaneous hydrolysis of the phosphate ester. While the AChE remains phosphylated, its enzyme activity is inhibited and therefore $\mathrm{ACh}$ accumulates in the synaptic clefts of muscles and nerves, leading to overstimulation of cholinergic receptors that is essentially "poisoning by endogenous ACh."

Additionally, OPCs may also interact (inhibit) with other serine esterases, ${ }^{34,35}$ may have a direct action on muscarinic and nicotinic receptors binding to (with high/low affinity) and modulating the function of these receptors, ${ }^{36}$ and may induce specific organ lesions. ${ }^{37}$ Propyl, isopropyl, butyl, and higher alkyl phosphates and phosphonates are more likely than methyl or ethyl analogs to act with secondary targets. ${ }^{35}$ The concentrations of OPCs required to act directly on nicotinic receptors are much higher than those on muscarinic receptors, suggesting that muscarinic receptors are more important as secondary targets in OPC action. Combination of possible interactions will produce resultant toxic effect(s) for the particular OPC. The spectrum of effects is further modulated by various toxicokinetic factors. ${ }^{38}$

In phase I of biotransformation, metabolic transformation of OPCs occurs through six major reactions, most of which are activation pathways: (1) oxidative desulfurations (conversion of thiophosphate to the more toxic oxon form, e.g., parathion, malathion, fenitrothion, diazinon, dimethoate, azinphosmethyl, fonofos), (2) oxidative N-dealkylation (e.g., dicrotophos, monocrotophos, dimethoate, phosphamidon), (3) oxidative O-dealkylation (e.g., chlorfenvinphos), (4) thioether oxidation (e.g., disulfoton, phorate, fenthion, demethon-S-methyl), (5) side chain oxidation (e.g., fenitrothion, diazinon), and (6) various nonoxidative reactions (e.g., trichlorfon, naled). In phase II of biotransformation, which is by definition, the detoxification phase, OPCs undergo conjugation with endogenous substrates, such as glucuronides and sulfates. Organophosphates are detoxified by the action of carboxylesterases (CarbE) (e.g., malathion, fentoate, soman, sarin, tabun), phosphorylphosphatases (e.g., pyrimiphos methyl, diazinon, paraoxon, DFP, soman, sarin, tabun) and glutathione redox system (e.g., methyl parathion, methyl paraoxon, fenitrothion, diazinon, dichlorvos, bromophos, chlorfenvinphos, mevinphos), but are activated by the cytochrome P450 system, NADPH-cytochrome P450 reductase and flavin-containing monooxygenases. ${ }^{39}$

CarbE plays an important role in the detoxification of OPCs via hydrolysis of ester bonds in OPCs (carboxyl ester side chain), as well as binding OPCs at the active site of CarbE that reduces the free concentration of the OPC potentially available to inhibit AChE. ${ }^{40}$ Differences in CarbE levels contribute to species differences in the toxicity of OPCs among mammals.

The most common pathway for the metabolism of OPCs is via hydrolysis, which results in removal of the more labile leaving group. Products of such hydrolysis are excreted in urine and are biomarkers of exposure. These include dimethylphosphate, dimethylthiophosphate, dimethyldithiophosphate, dimethylphosphorothioate, diethylphosphate, diethylthiophosphate, diethyldithiophosphate and diethylphosphorothioate. Because insecticidal OPCs differ mostly in the structure of the leaving group, the rates of hydrolysis will differ from compound to compound, despite similarity in some of the resulting urinary metabolites. ${ }^{41}$ The enzymes (phosphorylphosphatases) involved in hydrolysis of OPCs, and therefore inactivation, are present in many tissues and have high activities in liver, intestine and plasma.

Whether activation or detoxification will be a dominant reaction largely depends on the chemical structure of the OPC and its interaction with enzyme systems. Toxicity depends on the relative prevalence and intensity of these competing metabolic pathways. Chemicals that provoke induction of the enzymes involved in activation of OPCs can make them more toxic, as well as the chemicals that inhibit enzymes included in the detoxification phase and vice versa. ${ }^{40,42-44}$ However, clinical impact of interactions due to inhibition/induction of enzymes involved in detoxification or activation is difficult to predict because they often produce effects on several enzyme systems.

\section{Critical Toxic Effects}

Exposure to OPCs can induce four different clinical syndromes: (1) acute cholinergic crisis as a result of $\mathrm{AChE}$ inhibition, (2) intermediate syndrome whose underlying mechanism(s) is still unclear, (3) organophosphate-induced delayed neuropathy that has been explained by the inhibition of neuropathy target esterase, and (4) chronic organophosphate induced neuropsychiatric disorder due to long-term low-level exposure.

Acute cholinergic crisis immediately follows exposure to OPC and includes signs and symptoms resulting from hyperstimulation of muscarinic receptors (e.g., bradycardia, bronchoconstriction, bronchorrhoea, hypotension, increased gastrointestinal motility, abdominal cramps, miosis, hypersalivation), nicotinic receptors (e.g., hypertension, tachycardia, fibrillation, fasciculation, necrosis of striated muscles), and both central muscarinic and nicotinic receptors (e.g., tremor, movement incoordination, seizures, central depression of respiration, coma, death). If death ensues, it is usually due to asphyxia, i.e., after cessation of respiration followed by hypoxaemia and cyanosis. The so-called lung muscarinic syndrome (laryngospasm, bronchoconstriction and bronchorrhoea) and a depolarization paralysis of the respiratory muscles also contribute to the occurrence of asphyxia and death. Although the immediate cause of death could also be cardiac arrest or heart failure, central respiratory failure due to loss of respiratory drive is by far the most frequent cause of death after intoxication with OPCs. ${ }^{5}$

\section{Treatment of Organophosphate Poisoning}

The current view of the treatment of OPC poisoning includes three strategies: (1) the use of an anticholinergic drug (e.g., atropine), (2) cholinesterase-reactivating agents (e.g., oximes) and (3) anticonvulsant drugs (e.g., benzodiazepines). The development of treatment against OPC poisoning started with recognition of the efficacy of atropine as an antidote for their 
<smiles>C[n+]1ccccc1C=N</smiles>

PAM-2

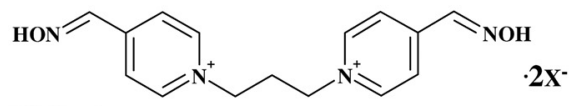

TMB-4

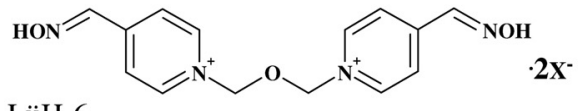

LüH-6

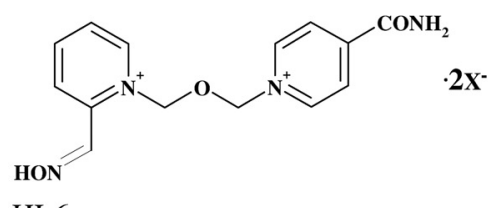

HI-6

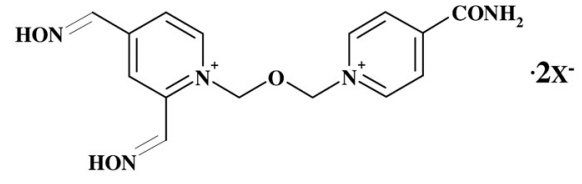

HLö-7

Figure 3. Structural formulas for pyridinium oximes.

parasympathomimetic effects. Atropine, an alkaloid isolated from Atropa belladonna L. by Main in 1835, first successfully used against a cholinesterase-inhibiting agent by Fraser in 1863, has remained the cornerstone of the therapy of OPC intoxication ever since. As far as chemical warfare agents are concerned, Eberhard Gross, after a remark that OPCs could exert their toxic action in a similar manner as carbamates (including physostigmine), suggested the use of atropine in the treatment of OPC poisoning. ${ }^{1}$ Experimental work performed after World War II has revealed that atropine affords much less efficient protection against OPCs than against carbamate intoxications, making atropine monotherapy insufficient in severe acute organophosphate poisoning. This is mainly due to the fact that atropine, as an antimuscarinic drug, is not capable of counteracting effects provoked by nicotinic hyperstimulation, while at the same time, possesses only limited antimuscarinic action in the central nervous system (CNS). Also, convulsions can be blocked by atropine only for a very limited time after exposure to OPCs since other transmitter systems have become involved in cholinergic overstimulation in the brain (e.g., $\gamma$-aminobutyric acid, glutamate). Nevertheless, atropine is the initial drug of choice in acute organophosphate poisoning.

The most important anticonvulsant in present use is diazepam. ${ }^{45,46}$ The combination of atropine and diazepam is more effective than atropine or oxime alone in reducing mortality. ${ }^{47}$ Basically, the benzodiazepines potentiate the action of the inhibitory neurotransmitter $\gamma$-aminobutyric acid at its receptors. ${ }^{48-51}$ In the cholinergic nervous system, diazepam probably decreases the synaptic release of ACh.52 The main consequence of the action of benzodiazepines in CNS is hyperpolarization of neurons which makes them significantly less susceptible to cholinergically-induced depolarization. The ultimate result is cessation of propagation of convulsions. ${ }^{53}$ Diazepam is of benefit in organophosphate poisoned patients by reducing anxiety, restlessness and muscle fasciculations, terminating convulsions, and reducing morbidity and mortality when used in conjunction with atropine and oxime. Diazepam should be given to patients poisoned with OPCs whenever convulsions or pronounced muscle fasciculation are present. In severe poisoning, diazepam administration should be considered even before these complications develop. ${ }^{54}$

\section{Oxime Therapy}

The first successful (in vitro) destruction of phosphylated AChE was accomplished by hydroxylamine in 1951.1 Additionally, in in vitro experiments, hydroxylamine also induced reactivation of AChE inhibited by tetraethylpyrophosphate. 55 In the following years, development of specific antidotes, originally aimed to regenerate $\mathrm{AChE}$ inhibited by nerve agents, has been based on the presumption that successful regeneration of inhibited enzymes could be achieved by the nucleophilic attack of a compound structurally similar to the chemical structure of $\mathrm{ACh}$, meaning a presence of a quaternary ammonia group in a molecule of reactivators. Namely, pralidoxime (PAM-2), the first pyridinium oxime, could reactivate the phosphylated enzyme about a million times faster than hydroxylamine. ${ }^{56}$ By 1956, the scientific public was introduced to the use of the newly synthesized oxime, PAM-2, which was administered against parathion poisoning in Japan. ${ }^{57}$ Further investigations in this area resulted in synthesis of bispyridinium oximes: trimedoxime (TMB-4), obidoxime (LüH-6), HI-6, and HLö-7 (figure 3). These oximes were synthesized and introduced as antidotes in 1957, 1964, 1967 and 1986, respectively.

PAM-2 (pyridinium-2-aldoxime) and TMB-4 $\mathrm{Cl}_{2}$ [1,3-Bis (4-hydroxyiminomethyl-1-pyridinio) propane dichloride] were synthesized in the United States. 58,59 Chemically, LüH-6 $\mathrm{Cl}_{2}$ is 1,3-Bis(4-hydroxyiminomethyl-1-pyridinio) -2-oxapropane dichloride. Oxime LüH-6 was named in honor of Lüttringhaus and Hagedorn who synthesized it in Germany and introduced it into the medical practice. ${ }^{60}$ An oxime named HI-6 $\mathrm{Cl}_{2}$ [1-(2-hydroxyiminomethyl1-pyridinio)-3-(4-carbamoyl-1-pyridinio)-2-oxapropane dichloride] was also synthesized by Hagedorn's group in Freiburg, Germany. ${ }^{61}$ The most recent Hagedorn oxime of importance (after LüH-6 and HI-6) was HLö-7, named after Hagedorn and Löffler. ${ }^{62}$ Chemically, this oxime is 1-(((4-(aminocarbonyl)pyridinio)methoxy)methyl)-2,4-bis ((hydroxyimino)methyl) pyridinium diiodide. Thus far, numerous attempts had been made to improve the antidotal properties of the conventional mono- and bis-pyridinium mono(di)-oximes by modifying their structure as well as by the introduction of other heterocyclic systems, such 
as imidazolium, quinuclidinium, pyridinium-imidazolium, pyridinium-quinuclidinium, and quinuclidinium-imidazolium compounds. ${ }^{26,63-69}$ Additionally, recent experimental studies conducted with 1,1'-methylene-bis(4-(hydroxyimino)methyl) pyridinium dibromide (MMB-4) showed that, compared to HLö-7 and HI-6, MMB-4 was a less potent reactivator of AChE inhibited by sarin, several sarin analogues, soman, VX, VR or CVX.3,70 Therefore, despite intensive research activities on this topic, PAM-2, TMB-4, LüH-6, HI-6 and HLö-7 have remained dominant among oximes in experimental work.

Commercially available oximes are PAM-2 salts (e.g., chloride, mesylate, methylsulphate, iodide) and LüH-6 chloride. TMB-4 and HI-6 were in clinical use, however, now these oximes are reserved for military use and are present in auto-injectors of several armies. ${ }^{71-73}$ Although there are no data on the clinical use of HLö-7, auto-injectors with this oxime were also developed. ${ }^{70}$

Pyridinium oximes were formulated as different salts (e.g., chloride, iodide, bromide, lactate, methylsulphate, methanesulfonate), which mostly differ in their stability and solubility. Generally, PAM-2, TMB-4 and LüH-6 are stable in aqueous solutions and can be prepared in liquid form in ampules, whereas HI-6 and HLö-7 are not stable in aqueous solutions and therefore can be kept for longer time only as powder that is dissolved immediately before use. ${ }^{74,75}$ Consequently, HI-6 and HLö-7 are formulated as dry/wet auto-injectors. Most papers on PAM-2 refer to the chloride or methanesulfonate (mesylate, P2S) salts. These salts replaced the first PAM-2 salt developed, PAM-2 iodide, because of its limited solubility. It was also reported that PAM-2 iodide might induce iodism. ${ }^{76}$ The anionic component of PAM-2, however, does not significantly influence its antidotal properties. $^{77}$

Comparative studies on the two salts of HI-6 (i.e., chloride and methanesulfonate) showed that HI-6 dimethanesulfonate (DMS) is much more soluble and that its absolute water-solubility is two and five times higher at $20^{\circ} \mathrm{C}$ and $5^{\circ} \mathrm{C}$, respectively..$^{78}$ Moreover, comparative studies on reactivation potency, pharmacokinetics and pharmacodynamics have demonstrated that the two HI-6 salts are equipotent in reactivating erythrocyte $\mathrm{AChE}$ inhibited by highly toxic OPCs and that the two HI-6 salts have a similar pharmacokinetic profile. ${ }^{79,80}$ In the frame of the Chemical Biological Radiological Nuclear Research and Technology Initiative, a project was launched aimed at developing auto-injectors based on HI-6 DMS. ${ }^{81}$ In the final stage of the project, preclinical efficacy and toxicology data for jointly administered HI-6 DMS, atropine and avizafone will be obtained that will enable a phase 1 clinical trial to be conducted, thereby determining the safety of the new nerve agent antidote system.

\section{Mechanism of Action of Pyridinium Oximes}

Reactivation of inhibited AChE by removal of the phosphyl moiety from the AChE active site serine is considered to be the primary mechanism of action for oximes. Clinical data obtained in organophosphorus pesticide-poisoned patients provide evidence for the validity of this assumption. ${ }^{82-84}$

As generally visualized, the oxime is oriented proximally to exert a nucleophilic attack on the phosphorus of the enzyme-inhibitor complex. Intermediate in the reactivation is a complex between the phosphylated enzyme and the reactivator. The enzyme-inhibitor-oxime complex is then split off, leaving the regenerated enzyme. However, phosphylated oximes formed during the reactivation process might be potent inhibitors of cholinesterases, which could cause re-inhibition of the previously reactivated enzyme. ${ }^{85}$ Re-inhibition of AChE can be faster than reactivation in the case when a phosphylated oxime inhibits the enzyme at a rate higher than that of its elimination or decay to non-toxic products. ${ }^{84,86}$

Early reports suggested this possibility on the basis of in vitro experiments with LüH-6 and dimethoate, ${ }^{87}$ and LüH-6 and PAM-2 with soman. ${ }^{88}$ Generally, phosphyloxime accumulation may occur in the many reactivation/ re-inhibition cycles, particularly with the more stable compounds deriving from 4-pyridinium oximes and may alter the efficacy of the 4-pyridinium oximes. ${ }^{89-91}$ It remains doubtful whether this occurs in humans with the usual dose regimens. It was also demonstrated that human paraoxonase with the prevailing Q192 phenotype $^{92}$ is able to hydrolyze effectively O,O-diethylphosphoryl LüH-6.93 This enzyme, however, is apparently unable to inactivate phosphonyl oxime derivatives. ${ }^{94}$

Mechanistic studies of oxime action have also shown that two binding sites are involved, i.e., cholinesterases have two binding sites for reversible ligands: (1) an acylation (catalytic) site at the base of the active site gorge and (2) a peripheral (allosteric) site at its mouth. ${ }^{95}$ Reversible ligands, such as the oximes, may bind to cholinesterases either at the catalytic site or at the allosteric site, or at both sites of the enzymes, thus explaining the mechanism of protection afforded by oxime administration. ${ }^{96}$ Bearing in mind the underlying mechanisms of reactivation and protection, it becomes clear that stereochemical arrangements of oximes can play a role in the difference in their therapeutic efficacy. Finally, so-called direct pharmacological effects such as direct reaction with OPCs, anticholinergic and sympathomimetic effects, as well as some pre-junctional properties that decrease the amount of liberated acetylcholine into the synaptic cleft,97-101 are also relevant for the interpretation of antidotal potency of oximes.

Regarding the aforementioned mechanism of protection, it is possible to administer oximes before the poisoning occurs, i.e., prophylactically. Oximes, as reversible ligands, protect cholinesterases from phosphylation by OPCs (i.e., oximes slow down the rate of phosphylation). ${ }^{26}$ Oximes might be able to reactivate the enzyme before a significant amount of aging has time to occur. This approach has been tried by the British who used P2S tablets as a pretreatment. ${ }^{102}$ However, short elimination half-lives of the oximes make them inappropriate for pre-treatment. ${ }^{83,103-105}$ Another prophylactic approach is a combination of cholinesterase and an oxime pre-treatment that 
has been explored as a pseudo-catalytic bioscavenger, such that the catalytic activity of inhibited cholinesterase can rapidly and continuously be restored in the presence of an oxime. ${ }^{28}$

\section{Clinical Use of Oximes}

A particular problem in interpreting the beneficial role and efficacy of oximes in clinical practice is a deficiency of published data, especially those evaluated in controlled clinical trials. In this section, in order to illustrate heterogeneity of therapeutic approaches (i.e., dose regimen, oxime choice and final outcome of the treatment) a few studies are presented in chronological order of publication.

Sixty patients acutely poisoned with various organophosphorus insecticides were treated with atropine, diazepam and HI-6 (500 mg every 6 hours intramuscularly) for 2 to 7 days, depending on the severity of the organophosphate poisoning. In addition, in a small series of patients $(\mathrm{n}=9)$, PAM-2 was administered instead in $1 \mathrm{~g}$ doses every 6 hours over the same period of time. The recovery of erythrocyte $\mathrm{AChE}$ was rapid in patients suffering from severe phorate, quinalphos, dichlorvos and pyridafenthion poisonings with reactivation half-lives ranging from 0.5 to 3.5 hours. Malathion-inhibited enzyme was reactivated much more slowly (reactivation half-life $=10.1$ hours), while HI-6 was ineffective against $\mathrm{AChE}$ inhibition caused by dimethoate and phosphoramidon. While nearly $100 \%$ reactivation of the enzyme was obtained after only 2 days of HI- 6 treatment, PAM- 2 could reactivate only $40 \%$ of the enzyme activity by the end of the eighth day. No adverse effects were noted in patients treated with oximes. ${ }^{82}$

Nine patients intoxicated with organophosphorus insecticides were treated with PAM-2 methylsulphate (Contrathion) using a dose of $4.42 \mathrm{mg} / \mathrm{kg}$ as a bolus injection followed by continuous infusion $2.14 \mathrm{mg} / \mathrm{kg} / \mathrm{h} .{ }^{106}$ In patients with ethylparathion and methylparathion poisonings, enzyme reactivation could be obtained in some at oxime concentrations as low as $2.88 \mathrm{mg} / \mathrm{L}$. In others, however, oxime concentration as high as $14.6 \mathrm{mg} / \mathrm{L}$ were ineffective. The therapeutic effect of the oxime seemed to depend on the plasma concentrations of ethylparathion and methylparathion. Due to enzyme AChE re-inhibition, reactivation was absent as long as these concentrations remained above $30 \mu \mathrm{g} / \mathrm{L}$.

In a series of five case reports, LüH-6 (Toxogonin) $250 \mathrm{mg}$ was given as an intravenous bolus followed by continuous infusion of $750 \mathrm{mg} / 24$ hours in cases of life-threatening parathion poisoning. This dose was effective, especially when the dose of parathion absorbed was relatively low. ${ }^{83}$

In a clinical study of 63 patients poisoned with organophosphorus insecticides, patients were divided into three groups: one was treated with atropine only, while the other two received atropine and either PAM-2 or LüH-6. Loading and maintenance intravenous doses for PAM-2 were $30 \mathrm{mg} / \mathrm{kg}$ and $8 \mathrm{mg} / \mathrm{kg} / \mathrm{h}$, respectively and $8 \mathrm{mg} / \mathrm{kg}$ and 2 $\mathrm{mg} / \mathrm{kg} / \mathrm{h}$, respectively, for LüH-6. There were no statistically significant differences in the major clinical findings or AChE activities on admission among the groups. Although the severity of intoxications (based on respiratory complications and duration of hospitalization) was higher in the atropine plus oxime groups, no mortality was found in the PAM-2 plus atropine group, whereas $12 \%$ and $50 \%$ of patients in the atropine and atropine plus LüH-6 groups died, respectively. Incidence of recurrent twitching and convulsions, repeated respiratory arrest, required mechanical respiration, required intensive care unit therapy and duration of hospitalization were smaller in the atropine plus LüH-6 group than in the atropine plus PAM-2 group. Three of the patients who received the LüH-6 combination therapy developed hepatitis and two of them died due to liver failure, which may indicate overdosage of LüH-6.107

The usual therapeutic regimen of LüH-6 is comprised of a $250 \mathrm{mg}$ intravenous (or intramuscular) bolus immediately after the first atropine injection. Then if no recovery is apparent during the next 15 to 30 minutes, an intravenous infusion of $750 \mathrm{mg} / 24 \mathrm{~h}$ is started for as long as necessary. Children can be treated with a $4 \mathrm{mg} / \mathrm{kg}$ bolus followed by an infusion with $0.45 \mathrm{mg} / \mathrm{kg} / \mathrm{h}$. PAM-2 chloride can be used according to the following scheme: $1 \mathrm{~g}$ intravenous bolus followed by up to $0.5 \mathrm{~g} / \mathrm{h}$ as an infusion. In children, a loading dose of 25 to $50 \mathrm{mg} / \mathrm{kg}$ PAM-2 can be used, followed by continuous infusion of 10 to $20 \mathrm{mg} / \mathrm{kg} / \mathrm{h} .{ }^{17}$ Other PAM-2 salts are also on the market (i.e., iodide, methylsulfate and mesylate) and can be used in corresponding doses.

\section{Drawbacks and Limitations of Oxime Therapy}

AChE inhibited by OPCs may undergo a secondary reaction, i.e., spontaneous dealkylation through alkyl-oxygen bond scission (aging), resulting in an irreversibly inactivated enzyme. Velocity of aging has a great impact on the treatment procedures and therapeutic efficacy of antidotes because aged enzyme cannot be reactivated by oxime therapy. The aging kinetics depend on the structure of the respective compound. Thus, OPCs leading to dimethylphosphoryl-AChE (e.g., malaoxon) have a much shorter aging half-life (about 4 hours) than compounds resulting in the diethylphosphoryl-enzyme (e.g., paraoxon, diazinon). ${ }^{108}$

Oximes are not equally effective and rank order of effectiveness changes with the OPC involved. Even if the same dosage regimen of an oxime is administered, due to interindividual variations, different plasma concentrations will be obtained. 109

Differences in their efficacy will be given not only throughout interactions with organophosphorus insecticides but also via their ability to counteract toxic effects of chemical nerve agents (sarin, soman, tabun, and VX). This approach is due to the permanent intention and effort of the scientific community to develop an oxime with universal antidotal properties, i.e., an oxime that is relatively efficient against all OPCs, including chemical nerve agents. ${ }^{69,110-113}$

PAM-2 is very efficient in reactivating AChE inhibited with sarin or VX, ${ }^{12,114-118}$ but is inefficient in the reactivation of 
the tabun-inhibited or soman-inhibited enzyme. ${ }^{119-121}$ Experiments have shown that TMB-4 is a powerful reactivator and was the first oxime efficient in the treatment of animals intoxicated with tabun $65,122,123$ and also effective against experimental sarin or VX poisoning. However, TMB-4 is totally ineffective against soman, ${ }^{65,119}$ and at the same time is the most toxic oxime demonstrated in mice to have a median lethal dose $\left(\mathrm{LD}_{50}\right)$ of 3, 4 and 8 times less than the ones for LüH-6, PAM-2 and HI-6, respectively. 97 Oxime LüH-6, recognized as a good $\mathrm{AChE}$ reactivator, shares similar antidotal properties with TMB-4. Although potent against tabun, sarin and VX, ${ }^{119,124} \mathrm{LuH}-6$ is also ineffective against soman poisoning in mice, ${ }^{65}$ guinea pigs ${ }^{119}$ and primates. ${ }^{125}$ LüH-6 is somewhat more efficient than TMB-4 as an antidote against tabun intoxication. ${ }^{126}$ Although being less toxic than TMB-4, this oxime shows hepatotoxic potential. 56,127

HI-6 is more potent than LüH-6 in protection of various rodent species from intoxication with soman, ${ }^{117,119,128}$ as well as sarin, and especially, VX. ${ }^{65}$ The only drawback of HI-6 is that this oxime cannot reactivate tabun-inhibited AChE. 129,130 The per se toxicity of HI-6 is low, actually the lowest among the aforementioned oximes. ${ }^{65,97,131}$

HLö-7 reactivates AChE inhibited by any of the four major nerve agents. ${ }^{132-134}$ In addition, HLö-7, more efficiently than PAM-2, LüH-6 and HI-6, restored the neuromuscular transmission impaired by in vitro superfusion of the neuro-muscular preparation with tabun, sarin, soman or cyclosarin. ${ }^{135}$ It was found that HLö-7 induced a significant reactivation of $\mathrm{AChE}$ in mice diaphragms previously inhibited with tabun, sarin, soman and cyclosarin. ${ }^{136}$ Although both HI-6 and HLö-7 can antagonize sarin-induced hypothermia (thus proving that they can pass the blood-brain barrier and gain access to the CNS when given with atropine), 136,137 the $\mathrm{LD}_{50}$ of HLö-7 is 2.5 times less than that of HI-6, indicating the higher per se toxicity of the newer oxime. ${ }^{136}$ The cardiovascular tolerability of HLö-7 was close, but still not as good as HI-6, at least in anesthetized guinea pigs. ${ }^{138}$ On the scale of efficacy, HLö-7 turned out to be somewhat more effective than HI- 6 against tabun and VX poisoning and less effective against sarin and soman, as well as cyclosarin intoxication. ${ }^{139,140}$ In guinea pigs, a species considered the closest model to the primate, HLö-7-induced protection against tabun poisoning was significantly better than that of HI-6, while HI-6 was only slightly more efficient than HLö-7 in soman poisoning. ${ }^{141}$

In cases of intoxications with organophosphorus insecticides, the worst therapeutic results are obtained with HI- 6 and HLö-7 and, to some extent, PAM-2, while the most efficient oximes are TMB-4 and LüH-6.83,142-144 Worek and co-workers $86,143,145$ have proved that equimolar concentrations of LüH- 6 are more effective than PAM-2, HI-6 and HLö-7 in in vitro reactivation of human erythrocyte AChE inhibited by several organophosphorus insecticides. Also, a $10 \mu \mathrm{mol} / \mathrm{L}$ concentration of LüH-6, ten times less than PAM-2 (100 $\mu \mathrm{mol} / \mathrm{L}$ ), was necessary to restore the contractility of isolated mouse diaphragm previously treated with paraoxon. Although efficient in patients intoxicated by low parathion doses, LüH-6 failed to antagonize the effects of high parathion doses, probably due to a high re-inhibition rate. ${ }^{83}$ However, in the same clinical study, LüH-6 was completely ineffective against oxydemethon-methyl intoxication. Unfortunately, there is no published clinical evidence on the use of TMB-4 in patients poisoned by organophosphorus insecticides; therefore, its comparison is impossible.

A clinical study of HI-6 administered intramuscularly at doses up to $500 \mathrm{mg}$ was performed in 22 healthy volunteers and revealed no adverse effects. In patients poisoned by several organophosphorus insecticides, HI-6 ensured fast reactivation of erythrocyte $\mathrm{AChE}$ in almost all cases, except in the cases of dimethoate and phosphamidon. 82,103

However, AChE inhibited by several organophosphorus insecticides, including dimethoate, demethon, triamiphos, ethoprophos, profenofos, fenamiphos and pyridafenthion, resists any attempt at reactivation with any oxime, probably due to variations in phosphoryl moiety and distribution of electronic charge. ${ }^{56,86,142}$ Finally, a systematic review of two randomized controlled clinical trials did not result in final proof of the efficacy of PAM-2 in the treatment of poisonings induced by organophosphorus insecticides in humans, ${ }^{146}$ probably due to the methodological gaps in the trials included, as indicated in the original publication.

\section{Conclusion}

There are many factors that influence oxime efficacy. Among them it seems most important to mention the inhibitory potential of OPCs and its toxicokinetics, aging kinetics of inhibited AChE, reactivating property of oximes, and its pharmacokinetics. However, the assessment of oximes effectiveness in patients severely poisoned with organophosphates is hampered by sedation, artificial ventilation and other therapeutic measures, as well as by varying individual clinical courses due to differences in type and amount of poison ingested or time elapsed before treatment starts. Substantial species differences hamper the extrapolation of experimental data to humans. Furthermore, frequently high and unrealistic doses/concentrations of oximes are chosen for the investigations, creating a serious problem for interpretation of experimental data. Aimed at overcoming these uncertainties, by combining different parameters, a promising dynamic model has been developed which may serve as a tool for defining effective oxime concentrations, for optimizing oxime treatment and for developing animal models. ${ }^{134,147}$ This model enables the simulation of dynamic changes in AChE activity by including enzyme kinetic (i.e., inhibition, reactivation, aging), pharmacokinetic and toxicokinetic parameters. Validation of the model using in vitro enzyme kinetic constants and distinct in vivo inhibitor and oxime concentrations demonstrated a good agreement between patient and calculated AChE activities for parathion poisoning treated with LüH-6.

Based on the results of the reactivation studies for organophosphorus insecticide-inhibited human AChE, LüH-6 seems to be the logical first choice therapy. However, due to 
the paucity of published clinical data, further studies are needed to establish the optimal therapeutic regimen. This comprises a permanent search for an oxime with universal antidotal characteristics, as well as carefully designed and harmonized protocols for experimental and clinical studies, thus enabling reliable data that can be implemented in comprehensive (re)assessment procedures with a minimum of uncertainties.

\section{References}

1. Karczmar AG. History of the research with anticholinesterase agents. In: Karczmar AG, Usdin E, Wills JH, eds. Anticholinesterase agents. Oxford: Pergamon Press;1970. 1-44.

2. Kuca K, Jun D, Cabal J, Hrabinova M, Bartosova L, Opletalova V. Russian VX: inhibition and reactivation of acetylcholinesterase compared with VX agent. Basic Clin Pharmacol Toxicol 2006;98:389-394.

3. Aurbek N, Thiermann H, Szinicz L, Eyer P, Worek F. Analysis of inhibition, reactivation and aging kinetics of highly toxic organophosphorus compounds with human and pig acetylcholinesterase. Toxicology 2006;224:91-99.

4. Cabal J, Bajgar J. Tabun - return following 50 years. Chem Listy 1999;93:27-31.

5. Ballantyne B, Marrs TC. Overview of the biological and clinical aspects of organophosphates and carbamates. In: Ballantyne B, Marrs TC, eds. Clinical and experimental toxicology of organophosphates and carbamates. Butterworth-Heinemann: Oxford Press; 1992. 3-14.

6. Karalliedde L, Eddleston M, Murray V. The global picture of organophosphate insecticide poisoning. In: Karalliedde L, Feldman F, Henry J, Marrs T, eds. Organophosphates and health. London: Imperial College Press; 2001. 431-473.

7. Kwong TC. Organophosphate pesticides: biochemistry and clinical toxicology. Ther Drug Monit 2002;24:144-149.

8. Eddleston M. Patterns and problems of deliberate self-poisoning in the developing world. QJM 2000;93:715-731.

9. Konradsen F, van der Hoek W, Cole DC, Hutchinson G, Daisley $\mathrm{H}$, Singh S, Eddleston M. Reducing acute poisoning in developing countries - options for restricting the availability of pesticides. Toxicology 2003;192:249-261.

10. Macilwain C. Study proves Iraq used nerve gas. Nature 1993;363:3

11. Black RM, Clarke RJ, Read RW, Reid MT. Application of gas chromatography-mass spectrometry and gas chromato graphy-tandem mass spectrometry to the analysis of chemical warfare samples, found to contain residues of the nerve agent sarin, sulphur mustard and their degradation products. J Chromatogr A 1994;662:301-321.

12. Nozaki H, Aikawa N, Fujishima S, Suzuki M, Shinozawa Y, Hori S, Nogawa S. A case of VX poisoning and the difference from sarin. Lancet 1995;346:698-699.

13. Nagao M, Takatori T, Matsuda Y, Nakajima M, Iwase H, Iwadate K. Definitive evidence for the acute sarin poisoning diagnosis in the Tokyo subway. Toxicol Appl Pharmacol 1997; 144:198-203.

14. Morita H, Yanagisawa N, Nakajima T, Shimizu M, Hirabayashi H, Okudera H, Nohara M, Midorikawa Y, Mimura S. Sarin poisoning in Matsumoto, Japan. Lancet 1995;346:290-293.

15. Tu AT. Anatomy of Aum Shinrikyoís organization and terrorist attacks with chemical and biological weapons. Arch Toxicol Kinet Xenobiot Metab 1999;7:45-84.

16. Worek F, Koller M, Thiermann H, Szinicz L. Diagnostic aspects of organophosphate poisoning. Toxicology 2005;214:182-189.

17. Zilker T. Medical management of incidents with chemical warfare agents. Toxicology 2005;214:221-231.

18. Abou-Donia MB. Organophosphorus pesticides. In: Chang LW, Dyer RS, eds. Handbook of Neurotoxicology. New York: Marcel Dekker;1995. 419-473.
19. Mileson BE, Chambers JE, Chen WL, Dettbarn W, Ehrich M, Eldefrawi AT, Gaylor DW, Hamernik K, Hodgson E, Karczmar AG, Padilla S, Pope CN, Richardson RJ, Saunders DR, Sheets LP, Sultatos LG, Wallace KB. Common mechanism of toxicity: a case study of organophosphorus pesticides. Toxicol Sci 1998;41:8-20.

20. Koelle GB. Anticholinesterase agents. In: Goodmann LS, Gilman A, Gilman AG, Koelle GB, eds. The pharmacological basis of therapeutics. New York: Macmillan;1975. 445-466.

21. Eyer P. The role of oximes in the management of organophosphorus pesticide poisoning. Toxicol Rev 2003;22:165-190.

22. Pope C, Karanth S, Liu J. Pharmacology and toxicology of cholinesterase inhibitors: uses and misuses of a common mechanism of action. Environ Toxicol Pharmacol 2005; 19:433-446.

23. Dale HH. The action of certain esters and ethers of choline and their relation to muscarine. J Pharmacol Exp Ther 1914;6:147-190.

24. Jokanovic M, Maksimovic M. Abnormal cholinesterase activity: understanding and interpretation. Eur J Clin Chem Clin Biochem 1997;35:11-16.

25. Thiermann H, Szinicz L, Eyer P, Zilker T, Worek F. Correlation between red blood cell acetylcholinesterase activity and neuromuscular transmission in organophosphate poisoning. Chem Biol Interact 2005;157-158:345-347.

26. Primozic I, Odzak R, Tomic S, Simeon-Rudolf V, Reiner E. Pyridinium, imidazolium, and quinucludinium oximes: synthesis, interaction with native and phosphylated cholinesterases, and antidotes against organophosphorus compounds. J Med Chem Def 2004;2:1-30.

27. Ashani Y, Shapira S, Levy D, Wolfe AD, Doctor BP, Raveh L. Butyrylcholinesterase and acetylcholinesterase prophylaxis against soman poisoning in mice. Biochem Pharmacol 1991;41:37-41.

28. Maxwell DM, Saxena A, Gordon RK, Doctor BP. Improvements in scavenger protection against organophosphorus agents by modification of cholinesterases. Chem Biol Interact 1999;119-120:419-428.

29. Li B, Duysen EG, Poluektova LY, Murrin LC, Lockridge O. Protection from the toxicity of diisopropylfluorophosphate by adeno-associated virus expressing acetylcholinesterase. Toxicol Appl Pharmacol 2006;214:152-165.

30. Ashani Y. Prospective of human butyrylcholinesterase as a detoxifying antidote and potential regulator of controlled-release drugs. Drug Dev Res 2000;50:298-308.

31. Doctor BP, Saxena A. Bioscavengers for the protection of humans against organophosphate toxicity. Chem Biol Interact 2005; 157-158:167-171.

32. Chilukuri N, Parikh K, Sun W, Naik R, Tipparaju P, Doctor BP, Saxena A. Polyethylene glycosylation prolongs the circulatory stability of recombinant human butyrylcholinesterase. Chem Biol Interact 2005;157-158:115-121.

33. Lotti M. Cholinesterase inhibition: complexities in interpretation. Clin Chem 1995;41:1814-1818.

34. Casida JE, Quistad GB. Organophosphate toxicology: safety aspects of nonacetylcholinesterase secondary targets. Chem Res Toxicol 2004;17:983-998.

35. Casida JE, Quistad GB. Serine hydrolase targets of organophosphorus toxicants. Chem Biol Interact 2005; 157-158:277-283

36. Bakry NM, el-Rashidy AH, Eldefrawi AT, Eldefrawi ME. Direct actions of organophosphate anticholinesterases on nicotinic and muscarinic acetylcholine receptors. J Biochem Toxicol 1988:3:235-259.

37. Cao CJ, Mioduszewski RJ, Menking DE, Valdes JJ, Katz EJ, Eldefrawi ME, Eldefrawi AT. Cytotoxicity of organophosphate anticholinesterases. In Vitro Cell Dev Biol Anim 1999;35:493-500. 
38. Karalliedde LD, Edwards P, Marrs TC. Variables influencing the toxic response to organophosphates in humans. Food Chem Toxicol 2003;41:1-13.

39. Jokanovic M. Biotransformation of organophosphorus compounds. Toxicology 2001;166:139-160.

40. Jokanovic M. Role of carboxylesterase in soman, sarin and tabun poisoning in rats. Pharmacol Toxicol 1989;65:181-184.

41. Moretto A, Lotti M. Monitoring of occupational exposures to organophosphorus compounds. In: Karalliedde L, Feldman S, Henry J, Marrs TC, eds. Organophosphates and health. London: Imperial College Press;2001. 431-473.

42. Boskovic B. The influence of 2-/o-cresyl/-4 H-1 : 3 : 2-benzodioxa-phosphorin-2-oxide (CBDP) on organophosphate poisoning and its therapy. Arch Toxicol 1979;42:207-216.

43. Clement JG. Role of aliesterase in organophosphate poisoning. Fundam Appl Toxicol 1984;4:S96-S105.

44. Jokanovic M, Kosanovic M, Maksimovic M. Interaction of organophosphorus compounds with carboxylesterases in the rat. Arch Toxicol 1996;70:444-450.

45. Lipp JA. Effect of diazepam upon soman-induced seizure activity and convulsions. Electroencephalogr Clin Neurophysiol 1972;32:557-560.

46. Sellström Å. Anticonvulsants in anticholinesterase poisoning. In: Ballantyne B, Marrs TC, eds. Clinical and experimental toxicology of organophosphates and carbamates. Oxford: Butterworth-Heinemann;1992. 578-586.

47. McDonough JH Jr, Jaax NK, Crowley RA, Mays MZ, Modrow HE. Atropine and/or diazepam therapy protects against soman-induced neural and cardiac pathology. Fundam Appl Toxicol 1989;13:256-276.

48. Guidotti A, Toffano G, Costa E. An endogenous protein modulates the affinity of GABA and benzodiazepine receptors in rat brain. Nature 1978;275:553-555.

49. Costa E, Guidotti A. Molecular mechanisms in the receptor action of benzodiazepines. Annu Rev Pharmacol Toxicol 1979;19:531-545.

50. Matsumoto K, Fukuda H. Stimulatory and protective effects of benzodiazepines on GABA receptors labeled with $[3 \mathrm{H}]$ muscimol. Life Sci 1982;30:935-943.

51. Skerritt JH, Willow M, Johnston GA. Diazepam enhancement of low affinity GABA binding to rat brain membranes. Neurosci Lett 1982;29:63-66.

52. Shih TM. Cholinergic actions of diazepam and atropine sulfate in soman poisoning. Brain Res Bull 1991;26:565-573.

53. McDonough JH Jr, Zoeffel LD, McMonagle J, Copeland TL, Smith CD, Shih TM. Anticonvulsant treatment of nerve agent seizures: anticholinergics versus diazepam in soman-intoxicated guinea pigs. Epilepsy Res 2000;38:1-14.

54. Marrs TC. Diazepam in the treatment of organophosphorus ester pesticide poisoning. Toxicol Rev 2003;22:75-81.

55. Childs AF, Davies DR, Green AL, Rutland JP. The reactivation by oximes and hydroxamic acids of cholinesterase inhibited by organo-phosphorus compounds. Br J Pharmacol Chemother 1955;10:462-465.

56. Bismuth C, Inns RH, Marrs TC. Efficacy, toxicity and clinical use of oximes in anticholinesterase poisoning. In: Ballantyne B, Marrs TC, eds. Clinical and experimental toxicology of organophosphates and carbamates. Oxford: Butterworth-Heinemann;1992. 555-577.

57. Namba T, Hiraki K. PAM (pyridine-2-aldoxime methiodide) therapy for alkyl-phosphate poisoning. J Am Med Assoc 1958;166:1834-1839.

58. Wilson IB, Ginsburg B. A powerful reactivator of alkylphosphate-inhibited acetylcholinesterase. Biochim Biophys Acta 1955;18:168-170.

59. Poziomek EJ, Hackley BE Jr, Streinberg GM. Pyridinium aldoximes. J Org Chem 1958;23:714-717.
60. Luettringhaus A, Hagedorn I. Quaternary hydroxyiminomethylpyridinium salts. The dischloride of bis-(4-hydroxyiminomethyl-1-pyridinium-methyl)-ether (lueh6), a new reactivator of acetylcholinesterase inhibited by organic phosphoric acid esters. Arzneimittelforschung 1964;14:1-5.

61. Hagedorn I, Gundel WH, Schoene K. Reactivation of phosphorylated acetylcholine esterase with oximes: contribution to the study of the reaction course. Arzneimittelforschung 1969;19:603-606.

62. Loffler M. Quartare Salze von Pyridin 2,4-dialdoxim als. Gegenmittel fur Organophosphat-Vergiftungen (dissertation). Freiburg, University of Freiburg, Germany, 1986.

63. Deljac V, Bregovec I, Maksimovic M, Rakin D, Markov V, Binenfeld Z. Chemical properties and protective effect of bis-pyridinium-2-monooxime carbonyl derivatives against inhibition of choline esterase by soman. Acta Pharm Jugoslav 1979;29:107-110.

64. de Jong LP, Wolring GZ. Reactivation of acetylcholinesterase inhibited by 1,2,2'-trimethylpropyl methylphosphonofluoridate (soman) with HI-6 and related oximes. Biochem Pharmacol 1980;29:2379-2387.

65. Maksimović M, Bošković B, Radović L, Tadić V, Deljac V, Binenfeld $\mathrm{Z}$. Antidotal effects of bis-pyridinium-2-monooxime carbonyl derivatives in intoxications with highly toxic organophosphorus compounds. Acta Pharm Jugoslav 1980;30:151-160.

66. Shih TM. Comparison of several oximes on reactivation of soman-inhibited blood, brain and tissue cholinesterase activity in rats. Arch Toxicol 1993;67:637-646.

67. Kassa J, Cabal J. A comparison of the efficacy of a new asymmetric bispyridinium oxime BI-6 with currently available oximes and $\mathrm{H}$ oximes against soman by in vitro and in vivo methods. Toxicology 1999;132:111-118.

68. Kuca K, Bielavsky J, Cabal J, Kassa J. Synthesis of a new reactivator of tabun-inhibited acetylcholinesterase. Bioorg Med Chem Lett 2003;13:3545-3547.

69. Kuca K, Bartosova L, Jun D, Patocka J, Cabal J, Kassa J, Kunesova G. New quaternary pyridine aldoximes as casual antidotes against nerve agents intoxications. Biomed Pap Med Fac Univ Palacky Olomouc Czech Repub 2005;149:75-82.

70. Bartling A, Worek F, Szinicz L, Thiermann H. Enzyme-kinetic investigation of different sarin analogues reacting with human acetylcholinesterase and butyrylcholinesterase. Toxicology 2006; [Epub ahead of print].

71. Spohrer U, Thiermann H, Klimmek R, Eyer P. Pharmacokinetics of the oximes HI 6 and HLo 7 in dogs after i.m. injection with newly developed dry/wet autoinjectors. Arch Toxicol 1994;68:480-489.

72. Kozer E, Mordel A, Haim SB, Bulkowstein M, Berkovitch M, Bentur Y. Pediatric poisoning from trimedoxime (TMB4) and atropine automatic injectors. J Pediatr 2005;146:41-44.

73. Bentur Y, Layish I, Krivoy A, Berkovitch M, Rotman E, Haim SB, Yehezkelli Y, Kozer E. Civilian adult self injections of atropine-trimedoxime (TMB4) auto-injectors. Clin Toxicol 2006;44:301-306.

74. Eyer P, Hagedorn I, Ladstetter B. Study on the stability of the oxime HI 6 in aqueous solution. Arch Toxicol 1988;62:224-226.

75. Eyer P, Ladstetter B, Schafer W, Sonnenbichler J. Studies on the stability and decomposition of the Hagedorn-oxime HLo 7 in aqueous solution. Arch Toxicol 1989;63:59-67.

76. Crook JW, Goodman AI, Colbourn JL, Zvirblis P, Oberst FW, Wills JH. Adjunctive value of oral prophylaxis with the oximes 2-PAM lactate and 2-PAM methanesulfonate to therapeutic administration of atropine in dogs poisoned by inhaled Sarin vapor. Pharmacol Exp Ther 1962;136:397-39

77. Dawson RM. Review of oximes available for treatment of nerve agent poisoning. J Appl Toxicol 1994;14:317-331. 
78. Thiermann H, Seidl S, Eyer P. HI 6 dimethanesulfonate has better dissolution properties than HI 6 dichloride in dry/wet autoinjectors. Int J Pharm 1996;137:167-176.

79. Krummer S, Thiermann H, Worek F, Eyer P. Equipotent cholinesterase reactivation in vitro by the nerve agent antidotes HI 6 dichloride and HI 6 dimethanesulfonate. Arch Toxicol 2002;76:589-595.

80. Lundy PM, Hill I, Lecavalier P, Hamilton MG, Vair C, Davidson C, Weatherby KL, Berger BJ. The pharmacokinetics and pharmacodynamics of two HI-6 salts in swine and efficacy in the treatment of GF and soman poisoning. Toxicology 2005;208:399-409.

81. Delaney J, Van Loon D. HI-6 Nerve Agent Antidote System (CRTI 0131TA). Proceedings of the 2006 CRTI Summer Symposium, June 13-15, 2006, Gatineau, Quebec, Canada. 21-22.

82. Kusic R, Jovanovic D, Randjelovic S, Joksovic D, Todorovic V, Boskovic B, Jokanovic M, Vojvodic V. HI-6 in man: efficacy of the oxime in poisoning by organophosphorus insecticides. Hum Exp Toxicol 1991;10:113-118.

83. Thiermann H, Mast U, Klimmek R, Eyer P, Hibler A, Pfab R, Felgenhauer N, Zilker T. Cholinesterase status, pharmacokinetics and laboratory findings during obidoxime therapy in organophosphate poisoned patients. Hum Exp Toxicol 1997; 16:473-480.

84. Thiermann H, Szinicz L, Eyer F, Worek F, Eyer P, Felgenhauer $\mathrm{N}$, Zilker T. Modern strategies in therapy of organophosphate poisoning. Toxicol Lett 1999;107:233-239.

85. de Jong LP, Ceulen DI. Anticholinesterase activity and rate of decomposition of some phosphylated oximes. Biochem Pharmacol 1978;27:857-863.

86. Worek F, Backer M, Thiermann H, Szinicz L, Mast U, Klimmek R, Eyer P. Reappraisal of indications and limitations of oxime therapy in organophosphate poisoning. Hum Exp Toxicol 1997;16:466-472.

87. Erdmann WD, Zech R, Franke P, Bosse I. On the problem of the therapeutic effectiveness of esterase reactivators in dimethoate poisoning. Arzneimittelforschung 1966;16:492-494.

88. Schoene K. Phosphonyloxime of soman; formation and reaction with acetylcholinesterase in vitro. Biochem Pharmacol 1973;22:2997-3003.

89. Leader H, Vincze A, Manisterski B, Rothschild N, Dosoretz C, Ashani Y. Characterization of O,O-diethylphosphoryl oximes as inhibitors of cholinesterases and substrates of phosphotriesterases. Biochem Pharmacol 1999;58:503-515.

90. Luo C, Saxena A, Smith M, Garcia G, Radic Z, Taylor P, Doctor BP. Phosphoryl oxime inhibition of acetylcholinesterase during oxime reactivation is prevented by edrophonium. Biochemistry 1999;38:9937-9947.

91. Ashani Y, Bhattacharjee AK, Leader H, Saxena A, Doctor BP. Inhibition of cholinesterases with cationic phosphonyl oximes highlights distinctive properties of the charged pyridine groups of quaternary oxime reactivators. Biochem Pharmacol 2003;66:191-202.

92. Brophy VH, Jampsa RL, Clendenning JB, McKinstry LA, Jarvik GP, Furlong CE. Effects of 5' regulatory-region polymorphisms on paraoxonase-gene (PON1) expression. Am J Hum Genet 2001;68:1428-1436.

93. Kiderlen D, Worek F, Klimmek R, Eyer P. The phosphoryl oxime-destroying activity of human plasma. Arch Toxicol 2000;74:27-32

94. Worek F, Eyer P, Kiderlen D, Thiermann H, Szinicz L. Effect of human plasma on the reactivation of sarin-inhibited human erythrocyte acetylcholinesterase. Arch Toxicol 2000;74:21-26.

95. Rosenberry TL, Johnson JL, Cusack B, Thomas JL, Emani S, Venkatasubban KS. Interactions between the peripheral site and the acylation site in acetylcholinesterase. Chem Biol Interact 2005;157-158:181-189.

96. Reiner E. Inhibition of acetylcholinesterase by 4,4'-bipyridin and its effect upon phosphorylation of the enzyme. Croat Chem Acta 1986;59:925-931.
97. Clement JG. Toxicology and pharmacology of bispyridium oximes - insight into the mechanism of action vs Soman poisoning in vivo. Fundam Appl Toxicol 1981;1:193-202.

98. Busker RW, Zijlstra JJ, van der Wiel HJ, Melchers BP, van Helden HP. Organophosphate poisoning: a method to test therapeutic effects of oximes other than acetylcholinesterase reactivation in the rat. Toxicology 1991;69:331-344.

99. Melchers BP, Van der Laaken AL, Van Helden HP. On the mechanism whereby HI-6 improves neuromuscular function after oxime-resistant acetylcholinesterase inhibition and subsequent impairment of neuromuscular transmission. Eur $\mathbf{J}$ Pharmacol 1991;200:331-337.

100. van Helden HP, de Lange J, Busker RW, Melchers BP. Therapy of organophosphate poisoning in the rat by direct effects of oximes unrelated to $\mathrm{ChE}$ reactivation. Arch Toxicol 1991;65:586-593.

101. Becker G, Kawan A, Szinicz L. Direct reaction of oximes with sarin, soman, or tabun in vitro. Arch Toxicol 1997;71:714-718.

102. Inns RH, Marrs TC. Prophylaxis against anticholinesterse poisoning. In: Ballantyne B, Marrs TC, eds. Clinical and Experimental Toxicology of Organophosphates and Carbamates. Oxford: Butterworth-Heinemann; 1992. 602-610.

103. Kusic R, Boskovic B, Vojvodic V, Jovanovic D. HI-6 in man: blood levels, urinary excretion, and tolerance after intramuscular administration of the oxime to healthy volunteers. Fundam Appl Toxicol 1985;5:S89-S97.

104. Jovanovic D. Pharmacokinetics of pralidoxime chloride. A comparative study in healthy volunteers and in organophosphorus poisoning. Arch Toxicol 1989;63:416-418.

105. Milic B, Maksimovic M, Nedelijkovic M. Trimedoxime and HI-6: kinetic comparison after intravenous administration to mice. Pharmacol Toxicol 1996;78:269-272.

106. Willems JL, De Bisschop HC, Verstraete AG, Declerck C, Christiaens Y, Vanscheeuwyck P, Buylaert WA, Vogelaers D, Colardyn F. Cholinesterase reactivation in organophosphorus poisoned patients depends on the plasma concentrations of the oxime pralidoxime methylsulphate and of the organophosphate. Arch Toxicol 1993;67:79-84.

107. Balali-Mood M, Shariat M. Treatment of organophosphate poisoning. Experience of nerve agents and acute pesticide poisoning on the effects of oximes. J Physiol Paris 1998;92:375-378

108. Skrinjaric Spojar M, Simeon V, Reiner E. Spontaneous reactivation and aging of dimethylphosphorylated acetylcholinesterase. Biochim Biophys Acta 1973;315:363-369.

109. Aragao I, Soares ME, Bastos ML, Lopes M. Continuous infusion of obidoxime and the importance of plasma levels monitoring in organophosphate poisoning. Intensive Care Medicine 1996;22(Suppl 3): S388. (Abstract 512)

110. Chennamaneni SR, Vobalaboina V, Garlapati A. Quaternary salts of 4,3' and 4,4' bis-pyridinium monooximes: synthesis and biological activity. Bioorg Med Chem Lett 2005; 15:3076-3080.

111. Kim TH, Kuca K, Jun D, Jung YS. Design and synthesis of new bis-pyridinium oxime reactivators for acetylcholinesterase inhibited by organophosphorous nerve agents. Bioorg Med Chem Lett 2005;15:2914-2917.

112. Musilek K, Kuca K, Jun D, Dohnal V, Dolezal M. Synthesis of the novel series of bispyridinium compounds bearing (E)-but2-ene linker and evaluation of their reactivation activity against chlorpyrifos-inhibited acetylcholinesterase. Bioorg Med Chem Lett 2006;16:622-627.

113. Petroianu GA, Arafat K, Kuca K, Kassa J. Five oximes (K-27, $\mathrm{K}-33, \mathrm{~K}-48, \mathrm{BI}-6$ and methoxime) in comparison with pralidoxime: in vitro reactivation of red blood cell acetylcholinesterase inhibited by paraoxon. J Appl Toxicol 2006;26:64-71. 
114. Johnson DD, Stewart WC. The effects of atropine, pralidoxime, and lidocaine on nerve-muscle and respiratory function in organophosphate-treated rabbits. Can J Physiol Pharmacol 1970;48:625-630.

115. Sidell FR, Groff WA. The reactivatibility of cholinesterase inhibited by VX and sarin in man. Toxicol Appl Pharmacol 1974;27:241-252.

116. Harris LW, Stitcher DL. Reactivation of VX-inhibited cholinesterase by 2-PAM and HS-6 in rats. Drug Chem Toxicol 1983;6:235-240.

117. Mesiæ M, Deljac A, Deljac V, Binenfeld Z, Kilibarda V, Maksimoviæ M, Kovaeeviæ V. Reactivators of acetylcholinesterase inhibited by organophosphorus compounds. Imidazole derivatives.2. Acta Pharm Jugoslav 1991;41:203-210.

118. Masuda N, Takatsu M, Morinari H, Ozawa T. Sarin poisoning in Tokyo subway. Lancet 1995;345:1446.

119. Inns RH, Leadbeater L. The efficacy of bispyridinium derivatives in the treatment of organophosphonate poisoning in the guinea-pig. J Pharm Pharmacol 1983;35:427-433.

120. Boskovic B, Jokanovic M, Maksimovic M. Effects of sarin, soman and tabun on plasma and brain aliesterase activity in the rat. In: Brzin M, Barnard EA, Sket D, eds.

Cholinesterases - fundamental and applied aspects.

Berlin-New York: Walter de Gruyter \& Co.; 1984. 365-374.

121. Koplovitz I, Stewart JR. A comparison of the efficacy of HI6 and 2-PAM against soman, tabun, sarin, and VX in the rabbit. Toxicol Lett 1994;70:269-279.

122. Schoene K, Oldiges H. Efficacy of pyridinium salts in tabun and sarin poisoning in vivo and in vitro. Arch Int Pharmacodyn Ther 1973;204:110-123.

123. Bokonjic D, Stojiljkovic MP, Stulic D, Kovacevic V, Maksimovic M. Application of response surface modeling on the efficacy of a HI-6/trimedoxime mixture against tabun and soman poisoning in rats. Arch Toxicol Kinet Xenobiot Metab 1993;1:223-232.

124. Maksimovic M, Kovacevic V, Binenfeld Z. Protective and reactivating effects of HI-6-toxogonin mixture in rats and guinea-pigs poisoned by nerve agents. Acta Pharm Jugosl 1989;39:27-33.

125. Hamilton MG, Lundy PM. HI-6 therapy of soman and tabun poisoning in primates and rodents. Arch Toxicol 1989;63:144-149.

126. Heilbronn E, Tolagen B. Toxogonin in sarin, soman and tabun poisoning. Biochem Pharmacol 1965;14:73-77.

127. Marrs TC. Toxicology of oximes used in treatment of organophosphate poisoning. Adverse Drug React Toxicol Rev 1991;10:61-73.

128. Oldiges H, Schoene K. Pyridinium and imidazolium salts as antidotes for soman and paraoxon poisoning in mice. Arch Toxikol 1970;26:293-305.

129. Clement JG. HI-6: reactivation of central and peripheral acetylcholinesterase following inhibition by soman, sarin and tabun in vivo in the rat. Biochem Pharmacol 1982;31:1283-1287.

130. Cetkovic S, Cvetkovic M, Jandric D, Cosic M, Boskovic B. Effect of PAM-2 Cl, HI-6, and HGG-12 in poisoning by tabun and its thiocholine-like analog in the rat. Fundam Appl Toxicol 1984;4:S116-S123.

131. Rousseaux CG, Dua AK. Pharmacology of HI-6, an H-series oxime. Can J Physiol Pharmacol 1989;67:1183-1189.

132. de Jong LP, Verhagen MA, Langenberg JP, Hagedorn I, Loffler M. The bispyridinium-dioxime HLo-7. A potent reactivator for acetylcholinesterase inhibited by the stereoisomers of tabun and soman. Biochem Pharmacol 1989;38:633-640.

133. Worek F, Widmann R, Knopff O, Szinicz L. Reactivating potency of obidoxime, pralidoxime, HI 6 and HLo 7 in human erythrocyte acetylcholinesterase inhibited by highly toxic organophosphorus compounds. Arch Toxicol 1998; 72:237-243.
134. Worek F, Szinicz L, Eyer P, Thiermann H. Evaluation of oxime efficacy in nerve agent poisoning: development of a kinetic-based dynamic model. Toxicol Appl Pharmacol 2005;209:193-202.

135. Alberts P. A new H-oxime restores rat diaphragm contractility after esterase inhibition in vitro. Eur J Pharmacol 1990;184:191-194.

136. Clement JG, Hansen AS, Boulet CA. Efficacy of HLo-7 and pyrimidoxime as antidotes of nerve agent poisoning in mice. Arch Toxicol 1992;66:216-219.

137. Clement JG. Central activity of acetylcholinesterase oxime reactivators. Toxicol Appl Pharmacol 1992;112:104-109.

138. Worek F, Szinicz L. Investigation of acute cardiovascular and respiratory toxicity of HLo 7 dimethanesulfonate and HI 6 dichloride in anaesthetized guinea-pigs. Pharmacol Toxicol 1993;73:91-95.

139. Eyer P, Hagedorn I, Klimmek R, Lippstreu P, Loffler M, Oldiges H, Spohrer U, Steidl I, Szinicz L, Worek F. HLo 7 dimethanesulfonate, a potent bispyridinium-dioxime against anticholinesterases. Arch Toxicol 1992;66:603-621.

140. Lundy PM, Hansen AS, Hand BT, Boulet CA. Comparison of several oximes against poisoning by soman, tabun and GF. Toxicology 1992;72:99-105.

141. Melchers BP, Philippens IH, Wolthuis OL. Efficacy of HI-6 and HLo-7 in preventing incapacitation following nerve agent poisoning. Pharmacol Biochem Behav 1994;49:781-788.

142. Jokanovic M, Maksimovic M. A comparison of trimedoxime, obidoxime, pralidoxime and HI-6 in the treatment of oral organophosphorus insecticide poisoning in the rat. Arch Toxicol 1995;70:119-123.

143. Worek F, Kirchner T, Backer M, Szinicz L. Reactivation by various oximes of human erythrocyte acetylcholinesterase inhibited by different organophosphorus compounds. Arch Toxicol 1996;70:497-503.

144. Antonijevic B, Bokonjic D, Stojiljkovic MP, Kilibarda V, Milovanovic ZA, Nedeljkovic M, Maksimovic M. Efficacy of trimedoxime in mice poisoned with dichlorvos, heptenophos or monocrotophos. Basic Clin Pharmacol Toxicol 2005;96:111-117.

145. Worek F, Diepold C, Eyer P. Dimethylphosphoryl-inhibited human cholinesterases: inhibition, reactivation, and aging kinetics. Arch Toxicol 1999;73:7-14.

146. Eddleston M, Szinicz L, Eyer P, Buckley N. Oximes in acute organophosphorus pesticide poisoning: a systematic review of clinical trials. QJM 2002;95:275-283.

147. Worek F, Szinicz L, Thiermann H. Estimation of oxime efficacy in nerve agent poisoning: a kinetic approach. Chem Biol Interact 2005;157-158:349-352.

\section{Author Affiliations}

Biljana Antonijevic

Institute of Toxicological Chemistry

Faculty of Pharmacy

University of Belgrade

Vojvode Stepe 450

11221 Belgrade, Serbia

Milos P. Stojiljkovic

Department of Biochemistry, Pharmacology \& Genetics

Odense University Hospital

University of Southern Denmark

Winsløwparken 19

DK-5000 Odense, Denmark 